\title{
Pode a testemunha modesta falar? A biomedicina em trânsito paradigmático
}

\section{| ${ }^{1}$ Alice Cruz |}

Resumo: Este ensaio discute a hipótese aventada por Boaventura de Sousa Santos, em Um discurso sobre as ciências, de que a ciência moderna atravessa uma transição paradigmática. Ancorando essa reflexão no campo disciplinar da biomedicina, buscar-se-á aprofundar a proposta para uma "dupla ruptura epistemológica" que promova a emergência de "um paradigma prudente para uma vida decente". A partir do exame dos filamentos ideológicos que urdem a matriz epistemológica da biomedicina, bem como da sua substanciação heterogênea enquanto prática social mediada por relações de poder, defender-se-á, num primeiro momento, que a "primeira ruptura epistemológica" entre a ciência moderna e o senso comum deteve um cunho preponderantemente discursivo, e que é, por conseguinte, na transformação desse nexo que, embora invisibilizado, não cessou de existir, que se poderá operar uma "dupla ruptura epistemológica”. Para isso, será proposto, com base na análise da expansão contemporânea do campo da biomedicina para a inclusão de objetos e metodologias que destabilizam as dicotomias modernas, que o saber fenomenológico, historicamente marginalizado, do paciente seja ponderado como um senso comum emancipatório que descerra o caminho para uma "epistemologia das consequências", transformando, com isso, a testemunha modesta da ciência moderna numa testemunha subalterna que fala a partir da densidade experiencial que abrange a amplitude social do posicionamento do corpo-próprio.
1 Faculdade de Economia/ Centro de Estudos Sociais da Universidade de Coimbra.

Endereço eletrônico: alicecruz5@gmail.com 
Em 1987, Boaventura de Sousa Santos avançava, em Um discurso sobre as ciências, a ideia de que a ciência moderna atravessa uma transição paradigmática, identificando sinais de crise na sua matriz epistemológica e defendendo quatro teses centrais para a emergência de um novo paradigma: "um paradigma prudente para uma vida decente" (SANTOS, 1987, p. 37).

Nas teses enunciadas pelo autor, subjaz a crescente porosidade entre as antinomias fundacionais do pensamento moderno ocidental que radicam numa ontologia que distingue a natureza da cultura, o corpo da mente, o objeto do sujeito. Se, na esteira deste processo, a separação clássica entre as ciências naturais e as ciências sociais penderia a um esboroamento sob a égide hermenêutica das segundas, um dos seus principais corolários seria a inclusão de critérios pragmáticos no fazer da ciência, reconfigurando-a num novo senso comum (SANTOS, 1987).

As hipóteses então levantadas foram posteriormente desenvolvidas pelo seu autor no contexto de uma meditação mais lata em torno do nexo entre justiça social e justiça cognitiva. Para o caso, importa salientar dois dos seus eixos centrais. O primeiro aprofunda a imbricação da ciência no projeto político da modernidade ocidental colonialista. $\mathrm{O}$ segundo explora as condições internas e externas à ciência, para uma ampliação da "primeira ruptura epistemológica" (SANTOS, 1989, p. 33 e 2000, p. 100) entre aquela e o senso comum, que transforme tanto a primeira, quanto o segundo, mediante uma "dupla ruptura epistemológica" (SANTOS, 1989, p. 39 e 2000, p. 101). Rejeitando quer uma concepção utópica, quer uma concepção distópica da ciência moderna, Santos contrapõe uma concepção contrahegemônica que a insere em constelações epistêmicas pluralistas, por si cunhadas de "ecologia de saberes" (SANTOS, 2006, p. 143 e 2007, p. 26).

Este ensaio discute as ideias de transição paradigmática (SANTOS, 1987), "dupla ruptura epistemológica" (SANTOS, 1989, p. 39 e 2000, p. 101) e "ecologia de saberes" (SANTOS, 2006, p. 143 e 2007, p. 26) a partir do campo disciplinar da biomedicina. Por um lado, esta discussão é motivada pelo caráter dúctil do que é comumente descrito como a medicalização ${ }^{1}$ das sociedades modernas. Se é indubitável que a epistemologia biomédica configurou modelos de explicação ontológica do humano (FOUCAULT, 1977a), esse processo assume expressões diferenciadas, deslizando entre a mercantilização da vida (LOCK, 2007) e apropriaçôes agenciais do biopoder por parte de sujeitos individuais e coletivos 
(PETRYNA, 2002; ROSE, 2007). Por outro lado, esta discussão é instigada

por uma turbulência no campo da biomedicina motivada pelo reconhecimento crescente da necessidade de incluir objectos e metodologias tradicionalmente retidos no exterior das suas fronteiras disciplinares.

Começarei, assim, por identificar os elementos matriciais que compõem o saber biomédico, conferindo uma atenção particular à sua substanciação enquanto relação social e à espessura ideológica dos seus processos classificatórios. Após o que, e acolhendo a crítica de Haraway (1996) aos estudos sociais sobre ciência, diligenciarei identificar lugares alternativos do sujeito do conhecimento, examinando a emergência de objetos controversos que destabilizam algumas das antinomias fundacionais da epistemologia científica. Finalmente, terminarei com uma consideração preliminar acerca do desenho de uma "ecologia de saberes" (SANTOS, 2006, p. 143 e 2007, p. 26) para o campo da saúde.

\section{Um conhecimento-soteriológico no interior do conhecimento-regulação}

No paradigma político da modernidade ocidental, Santos identifica uma tensão entre regulação e emancipação que se reproduz no plano epistemológico sob formas emancipatórias ou regulatórias de conhecimento (SANTOS, 2000).

A medicina que se desenvolveu historicamente no espaço da modernidade ocidental, denominada biomedicina devido ao seu enfoque na biologia humana (HAHN; KLEINMAN, 1983), comunga das mesmas assunçôes da ciência moderna, alegando uma neutralidade epistemológica que a tornaria universalmente válida e que justificaria uma aplicação impérvia ao contexto (LOCK; NGUYEN, 2010). Não obstante tal asserção objetivista, a epistemologia biomédica converteuse num pilar regulatório nas sociedades modernas, ao configurar o que Foucault descreveu como regimes de verdade (FOUCAULT, 1977a). Esse mesmo declive regulatório verifica-se no seu exercício enquanto prática social.

Acentuando progressivamente um reducionismo radicado na oposição entre res extensa e res cogitans (DESCARTES, 1938) ${ }^{2}$, que condena o corpo a uma existência amorfa e a mente a um exílio privilegiado, o desenvolvimento histórico dessa medicina desembocou, por um lado, numa matriz epistemológica desenhada pela "predominância do concreto" (HAHN; KLEINMAN, 1983, p. 321) e, por outro, na sua institucionalização como uma "ciência das doenças" 
(CAMARGO JR., 2005, p. 180), em que "o ser humano, que deveria ser o alvo da terapêutica, passa a ser mero instrumento ou intermediário da ação da droga sobre as doenças" (SOARES; CAMARGO JR., 2007, p. 68). Este reducionismo fisicalista conduziu a que o diálogo da medicina moderna com o corpo se tenha aprofundado no mesmo passo em que o diálogo com o sujeito se comprimia, tornando-se, por fim, numa técnica de inquérito com vista ao diagnóstico, realizada mediante uma "preocupação desprendida" (HAHN; KLEINMAN, 1983, p. 316) ou, como declara Foucault, "o olhar clínico tem essa paradoxal propriedade de ouvir uma linguagem no momento em que percebe um espetáculo" (FOUCAULT, 1977b, p. 122). Da aporia entre o corpo-objeto e o corpo-vivido (MERLEAU-PONTY, 1990) vingou a desqualificação da experiência do paciente face ao conhecimento biomédico. Logo, na esteira de Santos, é viável identificar a biomedicina com um "conhecimento-regulação" (SANTOS, 2000, p. 74).

Porém, às características apontadas, soma-se uma outra, menos patente nas análises construtivistas da biomedicina, mas densamente presente no contexto da prática clínica, e que remete para uma ambição soteriológica. ${ }^{3}$ Levar em conta a dimensão soteriológica da biomedicina permite entender como a combinação discursiva entre hermeticidade técnica e retórica salvífica contribui para o reforço da legitimação pública desse saber. Mas permite, sobretudo, recuperar o nexo terapêutico para uma análise construtivista que não falhe em iluminar as intencionalidades dos sujeitos na sua relação com a biomedicina, expressas no que Hahn (1995) descreve como fenomenologias de cura ou na emergência de uma cidadania biológica (PETRYNA, 2002; ROSE, 2007).

Contudo, se brechas existem, na relação social entre os sujeitos e a biomedicina, que debilitam o músculo normalizador da última, elas não parecem, ainda, capazes de metamorfosear a verticalidade do seu gesto. Para dar conta dessa ambivalência, vale a pena retornar a Santos que chama a atenção para o caráter processual do conhecimento, afirmando que "todo o conhecimento implica uma trajetória" (SANTOS, 2000, p. 74). Será menos no resultado da intervenção biomédica e mais na trajetória da produção do seu saber e prática que melhor se tomará o pulso à tensão entre emancipação e regulação, uma vez que é no âmago da relação médico-paciente que se produz, não apenas a normalização (CANGUILHEM, 1991) do último e, concomitantemente, do tecido social, mas também a sua subalternização enquanto agente epistêmico. 
Inviável como "conhecimento-emancipação" (SANTOS, 2000, p. 74), o saber biomédico insinua-se como um conhecimento de tipo soteriológico no interior do "conhecimento-regulação" (SANTOS, 2000, p. 74), que significa, enfim, "o colapso da emancipação na regulação" (SANTOS, 2000, p. 16), mas que não deixa de apontar a trajetória na produção de conhecimento como um espaço decisivo para a construção de um saber emancipatório.

Porém, e como afirma Santos (2007), os pilares da emancipação e da regulação têm uma ancoragem histórica precisa, designadamente entre as sociedades modernas imperiais, sendo necessário entrever outras molduras epistemológicas para os espaços sujeitos a formas de dominação colonial, onde o autor identifica uma tensão entre apropriação e violência. Para a reflexão que, aqui, se desenha, é, também, indispensável escorar historicamente as práticas biomédicas, examinando em maior profundidade a relação entre a substanciação do saber biomédico e o contexto político onde esta tem lugar, acautelando uma análise que abrevie a biomedicina num sistema de representações. O seguinte exemplo ilustra esta ideia.

Na década de 1990, despontaram formas inéditas de ativismo terapêutico nos Estados Unidos da América (BASTOS, 2002), quando grupos de pacientes de Aids forçaram a entrada nos laboratórios. Na mesma década, após o golpe de Estado no Haiti, refugiados que buscavam exílio nos Estados Unidos da América, foram aprisionados, durante dois anos, na base naval norte-americana de Guantánamo - sob o pretexto de serem portadores de Aids - onde foram sujeitos a maus-tratos e a práticas médicas autoritárias. Como explica Farmer (2005), esses refugiados colidiram com estruturas de políticas de imigração discriminatórias, endossadas por estruturas de opiniōes xenófobas.

Esse exemplo expõe respostas radicalmente opostas à mesma enfermidade, pelo mesmo Estado e pela mesma medicina, em face dos sujeitos a que se dirigem. Com efeito, a diversidade não é estranha à ciência moderna, cuja pretensão unitária vem sendo decomposta (GALISON; STUMP, 1996). Porém, o que os exemplos citados sugerem é que a apreciação da heterogeneidade das práticas científicas necessita atentar a níveis macrossociais de análise (SINGER; BAER, 1995) e, muito particularmente, a formas sistemáticas e estruturais de violência (FARMER, 2010) e às "linhas abissais" (SANTOS, 2007, p. 3) que permitem invisibilizá-la. No que respeita à biomedicina, não basta, portanto, 
examinar a sua colaboração na regulação e classificação social: é necessário, também, perscrutar a porosidade dessa disciplina a formulações nutridas por um “senso comum conservador" (SANTOS, 2000, p. 101) entelhado no interior das próprias nosologias biomédicas. Procurarei, em seguida, aprofundar esse nexo.

\section{O pendor discursivo da primeira ruptura epistemológica}

Com vista à discriminação do enlace entre a ciência moderna e o senso comum, o quadro analítico legado por Kuhn (2005) carece ser ampliado, por se circunscrever aos processos internos de produção de conhecimento científico. Auxilio-me, aqui, da análise de Fleck (1979) acerca da sifilologia moderna e da sua vinculação à reação de Wasserman como método de diagnóstico da sífilis. Na sua análise da edificação da sifilologia moderna, Fleck (1979) questiona diretamente o que é um fato, sugerindo um emparelhamento de elementos heterogêneos na sua produção e conferindo à ciência moderna o mesmo peso de historicidade do qual procura desagrilhoar-se.

Situando a origem histórica dessa disciplina em finais do século XV, o autor explica que, à época, a sífilis era confundida com outras doenças, sendo descrita por duas molduras interpretativas com ancoragens epistêmicas distintas (a astrologia, que lhe atribuía uma origem sexual e a religião, que a considerava uma punição divina de uma sexualidade pecaminosa) mas que reforçavam, em conjunto, a classificação de uma doença venérea. Na mesma altura, o sucesso terapêutico do uso do mercúrio pela prática farmacêutica circunscreveu um conjunto de sintomas associados à sífilis. Foi a interação entre essas diferentes formulações que engendrou o substrato no qual o conceito de sífilis encontrou definição. Em sentido idêntico, o autor descreve uma paisagem ideológica subjacente à descoberta da reação de Wasserman. $\mathrm{O}$ processo descrito pelo autor prefigura uma inversão do método científico, uma vez que aquele começou por formular um postulado acerca da associação entre a sífilis e o sangue, obtendo posteriormente, e como seu corolário, a corroboração empírica do mesmo.

A fundação da hansenologia moderna, encetada após a descoberta do agente etiológico da hanseníase, o Mycobacterium leprae, em 1873, por Gerhard H. A. Hansen, teve assento num processo similar (CRUZ, 2008). Antes de mais, evidencia-se um paradoxo entre a carência de corroboração empírica dos seus axiomas e a difusão hegemônica destes. A resolução analítica desse paradoxo 
contraria a antinomia, aventada por Sontag (1991), entre a moralização e a medicalização dos significados cunhados nas enfermidades. Se, em inícios do século XIX, a hanseníase era considerada uma desordem constitucional dos trópicos (EDMOND, 2006), a mobilidade populacional trazida pela expansão imperial acendeu temores de contaminação, suscitando a sua descrição como um "perigo imperial” (WRIGHT apud GOULD, 2005, p. 109). A cercania da enfermidade compeliu uma atenção por parte das elites médicas e políticas da época que conduziu à Primeira Conferência Internacional sobre Lepra, em 1897, da qual resultou a jurisdição biomédica no combate à hanseníase (PANDYA, 2003). Apesar do deficit de sustentabilidade científica, dado o fracasso em cultivar o bacilo in vitro e in vivo (BENCHIMOL; ROMERO SÁ, 2003) a hansenologia consolidou-se como "ciência normal" (KUHN, 2005, p. 29), e os seus postulados, que compreendiam uma etiologia microbiana, a transmissão por contágio (note-se que até então a hanseníase era genericamente tida como doença hereditária) e a necessidade de uma profilaxia segregacionista, foram adoptados de modo hegemônico (PANDYA, 2003). Na sua esteira, o espaço da leprosaria, erigido sob um modelo de internamento compulsivo das pessoas enfermas, reergueu-se entre as sociedades centrais (CRUZ, 2008).

Procurar compreender como uma disciplina débil se constituiu, num período de tempo manifestamente curto, num modelo paradigmático extremamente robusto, conduz à constatação da ancoragem da produção do conhecimento científico na ordem política coeva. Não cabendo, aqui, a sua análise detalhada, importa salientar que, esculpindo o cenário social e político da época, o enlace entre a centralização estatal higienista (FOUCAULT, 1977b) e a ideologia colonialista (GILROY, 2000) encorpou a classificação da hanseníase como uma "doença residual de atraso civilizacional" (CRUZ, 2008, p. 90). Já o exame da nosologia forjada nos alvores da hansenologia moderna, denuncia a persistência indelével do substrato metafórico bíblico e medieval. Muito embora sem nenhuma comprovação empírica, a transmissão do bacilo era implicitamente tida como resultante do contato físico direto. Ora, o século XIX europeu produziu uma ética de pureza, em associação com a teoria microbiana (DOUGLAS, 1991; LATOUR, 1984), segundo a qual a derme constituía um nicho para os germes e oferecia um meio de transporte entre corpos (VIGARELLO, 1985). Essa percepção encontrava associação direta com a representação bíblica e medieval do toque poluente como 
veículo de propagação da hanseníase. Evidência disso é a presença transversal do legado bíblico e medieval nos discursos médicos de então. Estes, não obstante declararem uma clivagem profunda com o primeiro (FALCÃO, 1900), faziam a defesa das mesmas estratégias segregacionistas que criticavam.

Como se viu, Fleck (1979) alerta para a porosidade entre elementos díspares na produção do conhecimento biomédico, ainda que sob uma aparente cisão entre eles. Contudo, o exame dos alvores da hansenologia moderna sugere que, para a legitimação do conhecimento científico como verdadeiro, a cisão não basta, é necessário, também, que os outros saberes sejam constituídos em crença. Ora, este é, precisamente, um dos mecanismos para o exercício da "primeira ruptura epistemológica" (SANTOS, 1989, p. 33 e 2000, p. 100) entre a ciência moderna e o senso comum. Todavia, tanto a análise da escultura da sifilologia (FLECK, 1979), quanto da hansenologia (CRUZ, 2008) modernas revela o cunho essencialmente discursivo da clivagem entre a ciência moderna e o senso comum. Se em ambos os casos se ensaiava, retoricamente, uma ruptura epistemológica, na prática teciam-se continuidades.

É nesse sentido que Latour afirma que "jamais fomos modernos" (LATOUR, 1994, p. 51). Identificando a modernidade com a "dupla invenção" (LATOUR, 1994, p. 30) que separou a política da ciência por intermédio de um trabalho de "purificação" (LATOUR, 1994, p. 16) entre humanos e não humanos, o autor argumenta que a modernidade só pôde constituir-se mediante um trabalho contíguo de mediação ou de "tradução" (LATOUR, 1994, p. 16) que suscitou a proliferação dos híbridos.

Por conseguinte, a demarcação entre ciência e opinião (NUNES, 2008), ao ocultar os trânsitos entre ambas, por um lado atalha a participação democrática dos leigos na produção de conhecimento e, por outro, faculta a invisibilização dos filamentos ideológicos que enredam os conteúdos científicos na ordem social. Significa isto que a relação entre a ciência moderna e o senso comum tem-se cingido a um senso comum de tipo conservador. Faço, aqui, referência à distinção de Santos entre "senso comum emancipatório" e "senso comum conservador" (SANTOS, 2000, p. 101). Se o senso comum remete para um conhecimento prático ancorado no mundo (contrariamente à ciência, que, para conhecer o mundo, dele se pretende demarcada e apartada), não deixa de deter um cunho cristalizador, uma vez que as suas formulações epistêmicas tendem a 
reforçar as hierarquias sociais que traçam esse elo. É nesse sentido que o autor propõe uma "dupla ruptura epistemológica" (SANTOS, 1989, p. 39 e 2000, p. 101) que transforme tanto a ciência moderna, quanto o senso comum.

Para o autor, é na reconciliação da causa com a intenção e na avaliação pragmática do conhecimento, particulares a um "senso comum emancipatório" (SANTOS, 2000, p. 101), que assenta a transformação da ciência moderna num "conhecimento prudente para uma vida decente" (SANTOS, 1987, p. 37). Nesse horizonte, revela-se necessário aprofundar, em primeiro lugar, o enlace entre a ciência moderna e um "senso comum conservador" (SANTOS, 2000, p. 101), mas também detalhar a nutrição do último por uma hegemonia económica e política historicamente situada que, por sua vez, sustenta a universalização da ciência moderna como "localismo globalizado" (SANTOS, 2001, p. 71). ${ }^{4} \mathrm{Ou}$ seja, o "senso comum conservador" (SANTOS, 2000, p. 101) deve ser interpelado e desvelado como produto da interseção entre a colonialidade do poder e do saber (QUIJANO, 2008) no sistema-mundo capitalista (WALLERSTEIN, 2007).

Foi a crítica pós-colonial que desvelou o enraizamento da interseção entre saber e poder, identificada por Foucault (1977a), num processo de construção de uma hegemonia global que legitimou uma particular posição do sujeito do conhecimento como universal. A última tendo sido detalhadamente desencoberta por Haraway (1992), na desconstrução que realizou, a partir da análise da primatologia moderna, do postulado que distingue fato de ficção na escultura científica da natureza. Com efeito, terá sido, seguramente, a crítica feminista ${ }^{5}$ a que mais avançou na exposição da porosidade da ciência moderna a um "senso comum conservador" (SANTOS, 2000, p. 101) entalhado numa determinada hegemonia política. ${ }^{6}$ Os estudos de Martin (2007) acerca da biologia reprodutiva são exemplo disso.

Martin (2007) analisou os compêndios científicos usados nas faculdades de medicina dos Estados Unidos da América, nos quais averiguou o recurso estilístico a metáforas densamente imbuídas de estereótipos de gênero na descrição da reprodução humana. Sugestivamente, Martin apelida o retrato da relação entre as personagens centrais da saga reprodutiva, o óvulo e o espermatozóide, como "um conto de fadas científico" (MARTIN, 2007, p. 417). A primeira constatação da autora é a de que se os órgãos reprodutivos feminino e masculino são ambos descritos como sistemas que visam à produção de substâncias de valor, como o óvulo e o espermatozóide, os mesmos são objeto de uma apreciação antagônica, 
que inscreve no primeiro a improdutividade e a degenerescência e celebra no segundo a produtividade e a vitalidade. Essas descrições conduzem a uma classificação hierarquizada dos sistemas reprodutivos feminino e masculino que identificam a mulher não só como improdutiva, mas também como desperdiçadora. Como Martin (2007) frisa, a questão que se coloca é a de saber por que a vasta produção masculina de esperma não é, igualmente, percebida como desperdiçadora. Para a autora, a resposta a essa perplexidade remete aos estereótipos de gênero presentes na descrição científica do comportamento dos óvulos e dos espermatozóides, que retrata os primeiros como passivos, sendo incapazes de se movimentarem sozinhos, e os segundos como enérgicos, sendo os promotores ativos do processo de fecundação:

O quadro mais comum - o óvulo como uma dama em apuros, protegido apenas pelas suas vestimentas sagradas; o esperma como um guerreiro heroico em sua defesa - não pode ser provado como sendo ditado pela biologia desses acontecimentos. Embora os "fatos" da biologia possam não ser sempre construídos em termos culturais, neste caso eu argumentaria que são. (MARTIN, 2007, p. 420).

O que a análise de Martin (2007) permite, igualmente, perceber é o modo como os conteúdos culturais das representações científicas se entrincheiram nos processos de reavaliação das últimas. Perante novas evidências, a revisão do discurso na literatura biomédica, em vez de descartar estereótipos de gênero, parece reinventá-los. Assim, quando se reconheceu o papel ativo do óvulo, redundou-se num outro estereótipo, dessa feita o da mulher como predadora. Ainda que atribuindo ao óvulo maior protagonismo no processo de fecundação, a linguagem científica continua cativa de um senso comum marcado por estereótipos de gênero.

Em síntese, a "primeira ruptura epistemológica" (SANTOS, 1989, p. 33 e 2000, p. 100) não rompeu inteiramente com o senso comum. Por um lado, como explica Nunes (2008), a demarcação entre a ciência e outros saberes é um processo contingente e, por outro, como afirma Harding (1998), não é possível à ciência desvincular-se do seu lastro cultural:

Não é a sua aptidão para imunizar os seus relatos da ordem da natureza de todos os elementos culturais presentes na sua produção e uso que é responsável pelos seus grandes sucessos, como se tem presumido. Ao contrário, é a aptidão para neutralizar alguns desses elementos culturais, ao mesmo tempo que se explora plenamente outros que tem sido responsável tanto pelos seus sucessos, quanto pelos seus fracassos. (HARDING, 1998, p. 7). 
Parte da tarefa da "primeira ruptura epistemológica" (SANTOS, 1989, p. 33 e 2000, p. 100) terá sido a de ocultar a continuidade entre a ciência e o senso comum. Nessa ocultação repousa a legitimação do conhecimento científico como verdadeiro, mas repousa, também, o freio para o seu questionamento público. Parece, pois, ser por meio da transformação desse nexo que se poderá operar uma “dupla ruptura epistemológica” (SANTOS, 1989, p. 39 e 2000, p. 101).

Ora, segundo as teses desenvolvidas por Santos (1987), em Um discurso sobre as ciências, indicia-se uma transição paradigmática na ciência moderna que impele a última a reconhecer o recorte local e relacional das suas raias epistemológicas e metodológicas, por um lado, e a encetar um diálogo interdisciplinar no seu interior, mas também com atores externos, por outro. Como o próprio autor não falhou em reconhecer, as suas teses detêm um caráter especulativo, o que induz a que mereçam ser apreciadas com base nas motrizes de disciplinas científicas específicas. Uma vez questionada a pretensão de unicidade da ciência moderna (GALISON e STUMP, 1996), é presumível uma concomitante diversidade nas suas dinâmicas de mudança. Logo, com vista a essa ponderação, retorno, de seguida, ao campo da biomedicina.

\section{A biomedicina em trânsito paradigmático}

Assiste-se à emergência de objetos e metodologias que, ao forçarem a entrada no campo da biomedicina em resposta à pressão social por uma humanização dos cuidados de saúde, dialogam com preocupações e perspectivas tradicionalmente trabalhadas pelas ciências sociais. Refira-se o autocuidado (OREM, 2004), os cuidados paliativos (CARDOSO, 2005), a emergência da bioética (PÁLSSON; HARDARDÓTTIR, 2002) ou o reconhecimento do "gradiente social na saúde" (MARMOT, 2006, p. 2)

Para aprofundar essa desestabilização pragmática, é particularmente adequado considerar o cuidado da dor, uma vez que este implica um esboroamento de fronteiras ainda mais fortemente consolidadas pela epistemologia moderna, aquelas que apartam a mente do corpo e o sujeito do objeto do conhecimento. O cuidado da dor desfralda, com particular claridade, a necessidade da ciência encetar um diálogo horizontal com um "senso comum emancipatório" (SANTOS, 2000, p. 101) que valorize, concomitantemente, a autonomia do paciente no processo terapêutico.? 
A dor manifesta-se como experiência que, paradoxalmente, não pode ser nem negada, nem confirmada. Como explica Scarry (1985), a dor é desprovida de intencionalidade, contraindo um cunho autorreferencial. Por conseguinte, a sua experiência colide numa dificuldade de tradução que parece conter o indivíduo em si mesmo. É nesse sentido que Scarry (1985) descreve a dor como resistindo à objetificação pela linguagem. Ademais, como sublinha Jackson (1994), a invisibilidade da dor reforça a sua incomunicabilidade, uma vez que a sua existência só pode ser averiguada mediante afirmação de quem a experiencia.

Como tal, no universo biomédico a dor assoma como um objeto intangível, na ótica do terapeuta, ainda que insofismável, na experiência do paciente. Face à impossibilidade de localizar empiricamente as causas da dor (sobretudo quando a sua persistência a converte numa condição crônica) e de quantificar a sua amplitude, a dúvida instala-se (KLEINMAN et al., 1994). Carecendo de corroboração empírica e resistindo a modelos de explicação universais, a dor constitui-se numa "categoria clínica sem sanção oficial, uma categoria anômala" (KLEINMAN et al., 1994, p. 4).

Se, por um lado, o reducionismo biológico falha em localizar e quantificar a dor, por outro, a inadequação do primeiro agudiza-se perante a ocupação pela segunda dos espaços sociais que envolvem os sujeitos, como a família ou o trabalho, substanciando o campo experiencial e formativo da dor além das fronteiras que delimitam o corpo individual. Neste sentido, a dor é não apenas um objeto incompleto, segundo uma perspectiva reducionista, mas é, também, um objeto multifacetado que desafia as dicotomias modernas (KLEINMAN et al., 1994).

Pode-se afirmar, então, que o aparato tecnológico desenvolvido pela biomedicina para perscrutar o corpo humano fracassa perante a dor. Na verdade, ela esquiva-se ao olhar biomédico, aninhando-se em espaços fenomenológicos invisíveis que forçam o aprimoramento da auscultação como técnica de inteligibilidade necessariamente dialógica e intersubjetiva. Perante a dor, de nada serve ao conhecimento biomédico a profundidade do seu olhar, dada a superficialidade com que escuta.

Ora assiste-se a uma preocupação crescente com o cuidado da dor. Sua inclusão, não mais como sintoma de outras enfermidades, mas como uma afecção específica, vem desenhando, desde a década de 1970, um campo de atuação terapêutica segundo linhas que transgridem a ortodoxia biomédica 
(LIMA; TRAD, 2008). Estas incluem a redefinição conceptual da dor, com a concomitante transformação nas metodologias de diagnóstico e de tratamento. A definição corrente de dor descreve:

Uma experiência multidimensional desagradável, envolvendo não só um componente sensorial mas, também, um componente emocional e que se associa a uma lesão tecidular concreta ou potencial, ou é descrita em função dessa lesão. (IASP apud DGA, 2008, p. 6).

Por um lado, essa definição abre brechas no paradigma biomédico, ao problematizar a epidemiologia da dor e descartar o emprego de testes de referência para o seu diagnóstico (VERHAAK et al., 1998). Por outro lado, muito embora se ausente dessa concepção o reconhecimento de determinantes sociais da dor (VALLA, 2005), ela não deixa de abarcar as implicações relacionais e sua inteligibilidade contextual. Significa isto que a dor emerge como objeto de fronteira entre as ciências naturais e as ciências sociais, uma vez que, em vez de facilitar o seu arrumo quer na natureza, quer na cultura, ilumina um processo de co-construção entre a biologia e a socialidade humanas. Esse reconhecimento está na base de uma abordagem multidisciplinar do tratamento da dor (CARDOSO, 1999). Por outro, a irredutibilidade da dor a modelos explicativos com assento na padronização do corpo-objeto, impõe a presença do historicamente marginalizado e silenciado corpo-vivido na produção do diagnóstico e das subsequentes estratégias terapêuticas:

Esse movimento incita o médico clínico a romper com alguns dos cânones da biomedicina - a objetividade e o distanciamento - aproximando-o da clínica enquanto prática eminentemente interpretativa e hermenêutica. (LIMA e TRAD, 2008, p. 7)

Na verdade, a dor detém não apenas um caráter subjetivo, mas assume, também, uma variabilidade idiossincrática (GIORDANO; SCHATMAN, 2008). Logo, a entrada das ciências sociais no campo disciplinar da biomedicina demanda a entrada simultânea de um saber não científico, tecido no cotidiano pela experiência. O cuidado da dor conduz, igualmente, a uma autorreflexão na biomedicina para a equação de uma ética pragmática, construída na prática clínica cotidiana, e irredutível a critérios universais (GIORDANO; SCHATMAN, 2008).

Em suma, a constituição da dor em objeto para a biomedicina, acarreta um enfraquecimento dos seus sustentáculos, escorados nas antinomias de inspiração cartesiana, e uma destabilização das suas fronteiras disciplinares: 
Por um lado, a dor crônica, objeto insubordinado que escapa em muitos sentidos ao paradigma biomédico, transgride os backgrounds da racionalidade empiricista e cria situações ameaçadoras dos saberes e das práticas da arena profissional no cuidado da saúde. Por outro, abre oportunidades para repensar e refazer, de muitas maneiras, os caminhos. (LIMA; TRAD, 2008, p. 128).

Todavia, persistem resistências (JACKSON, 1994) que obstam ao almejado "projecto da humanização em dor crónica" (PAIVA, 2007, p. 63). Estas devem ser entendidas à luz de uma "ideologia da cura" (GARLAND-THOMSON, 2001, p. 264) veiculada pela biomedicina, que colabora na sustentação de um bloco hegemônico, como diria Gramsci (1994) - lembrando que o conceito de hegemonia remete para a diálise entre relações sociais de produção e a transversalidade ideológica entre as diferentes classes sociais que compõem as primeiras -, e que hoje expande a dominação clássica do corpo como força produtiva para a sua apropriação como uma mercadoria (LOCK, 2007). Nesse sentido, a mercantilização (PETRYNA; KLEINMAN, 2006) e a farmaceuticalização (BIEHL, 2007) da saúde encorpam a interseção entre a colonialidade do poder e a colonialidade do saber (QUIJANO, 2008) que enforma a biomedicina como um sistema hegemônico que, estando emparelhado em relações de dominação de tipo macro, reforça as últimas no nível social micro, como diriam Singer e Baer (1995).

Todavia, a discussão que objetos e metodologias controversas, como a dor e o seu cuidado, instigam no seio da biomedicina, evidencia uma turbulência epistemológica apta a induzir uma transição paradigmática. Indubitavelmente, este é um processo embrionário. Ademais, a substanciação dessa turbulência poderá, apenas, ser avaliada contextualmente. Tendo em vista a heterogeneidade das práticas biomédicas e das agências sociais que lhes respondem (LOCK; KAUFERT, 1998), esse processo assumirá expressões diferenciadas em função do contexto social e dos seus atores. Não obstante, a discussão que instiga no seio da biomedicina não deixa de constituir evidência de um processo de transição paradigmática.

$\mathrm{Na}$ verdade, uma das potencialidades da ideia de transição paradigmática (SANTOS, 1987) reside no seu caráter dinâmico. Formulações exploratórias de modos de conhecimento não dualistas e pluralistas escapam a quadros conclusivos como o de revolução científica (KUHN, 2005). Nesse sentido, mais do que confirmadas ou refutadas, as hipóteses lançadas por Santos (1987) abrem espaços hermenêuticos que permitem operacionalizar brechas na ciência moderna que, como aponta Haraway (1996), correm o risco de ser invisibilizadas pelos quadros 
metodológicos e analíticos canônicos dos estudos sociais sobre ciência. Ora, o que a dor, enquanto "objeto insubordinado" (LIMA; TRAD, 2008, p. 128), permite ponderar é que o dialogismo entre a ciência moderna e outros saberes só será simétrico na medida em que, a par com uma discussão plural dos usos do conhecimento científico, inclua esses saberes outros na "trajetória" (SANTOS, 2000, p. 74) da produção de conhecimento. Isso conduz à reflexão final deste ensaio.

\section{O desenho de uma ecologia de saberes no campo da saúde}

Ao contrário de Harding, (1998) que propõe uma diluição do privilégio epistêmico da ciência moderna por intermédio do reconhecimento de "qualquer tentativa sistemática de produzir conhecimento sobre o mundo natural” (HARDING, 1998, p. 10) como ciência, Santos (2007) defende que esse privilégio só poderá ser superado com um uso contra-hegemônico da ciência que explore os seus limites internos e externos e a insira em constelações plurais de saberes:

Trata-se de uma ecologia porque assenta no reconhecimento da pluralidade de saberes heterogêneos, da autonomia de cada um deles e da articulação sistêmica, dinâmica e horizontal entre eles. A ecologia de saberes assenta na independência complexa entre os diferentes saberes que constituem o sistema aberto do conhecimento em processo constante da criação e renovação. (SANTOS, 2007, p. 145)

Embora promova a horizontalidade entre diferentes saberes, a sua proposta não elide a necessidade de uma hierarquia que evite o relativismo. Ora essa hierarquia, em vez de se fundar na presunção da superioridade de um modelo epistemológico face a outros, radica em critérios pragmáticos de uma avaliação contextual e pontual dos saberes, mediante uma "epistemologia das consequências" (SANTOS, 2007, p. 33).

Como tal, a sua proposta inverte a validação do conhecimento da sua capacidade em aferir as causas que subjazem ao objeto por si desenhado, para o tipo de resultados na vida social produzidos pelo próprio desenho que faz do objeto. Isto implica deslocar a validação do laboratório para os universos fenomenológicos da experiência. Como explica Nunes (2008), se esse passo situa o valor da teoria na sua substanciação prática, também alcança a possibilidade de diálogo com saberes historicamente subalternizados.

Entende-se, assim, a maior amplitude da proposta de Santos (2007) face à proposta de Harding (1998), para o campo da biomedicina. Não discutindo, aqui, os potenciais corolários do uso semântico de ciência para designar outros 
saberes, fica claro que, no caso da biomedicina, o critério de "qualquer tentativa sistemática de produzir conhecimento sobre o mundo natural" (HARDING, 1998, p. 10) reproduziria a exclusão do saber experiencial dos pacientes. Porém, esse saber, como se viu para o caso do cuidado da dor, é determinante para o alcance de resultados satisfatórios. Ademais porque, se é apreciável a pulverização heterogênea do saber científico em dependência do contexto, não o é menos a diversidade das respostas sociais a esse saber. Como tal, Pálsson e Hardartóttir defendem a utilidade do conceito de "paisagens morais" (PÁLSSON; HARDARTÓTTIR, 2002, p. 272) para dar conta da heterogeneidade das respostas sociais aos desenvolvimentos biotecnológicos, auxiliando a ancoragem local das tomadas de decisão sobre os seus usos.

Por conseguinte, um uso contra-hegemônico da ciência moderna pressupóe a transfiguração de uma das estratégias centrais da gesta científica, designadamente esse modo modesto de testemunhar a produção de dados objetivos sobre o real:

Serviam para representar o autor como um observador desinteressado e os seus relatos como espelhos límpidos e exatos da natureza. Tal autor demonstrava sinais de um homem cujo testemunho era fidedigno. Consequentemente, os seus textos podiam ser creditados e o número de testemunhas das suas narrativas experimentais podia ser indefinidamente multiplicado. (SCHAPIN; SCHAFFER, 1985, p. 69)

Haraway (1996) distingue apuradamente o processo pelo qual o sujeito do conhecimento científico se converte intencionalmente em transparente, do processo pelo qual outros sujeitos, historicamente subalternizados, são forçados à transparência. Em contrapartida, a autora propõe uma difracção que densifique a testemunha do conhecimento científico com vista ao realinhamento do técnico com o político.

No campo disciplinar que tem sido objeto deste ensaio, a configuração de uma "ecologia de saberes" (SANTOS, 2006, p. 143 e 2007, p. 26) obriga à inclusão da voz experiencial dos sujeitos que falam a partir da densidade do corpo-próprio. Porém, se a intervenção das tecnologias biomédicas intenta confinar-se ao espaço delimitado pelo corpo individual, uma avaliação fenomenológica das mesmas é inseparável dos universos afetivos, sociais, culturais e políticos a partir dos quais é vocalizada. Por conseguinte, o saber experiencial dos sujeitos ${ }^{8}$ configura um "senso comum pragmático" (SANTOS, 2000, p. 101), informado pela objetividade forte de um conhecimento situado (HARDING, 2002; HARAWAY, 1988), entendida, aqui, não como reificação essencialista, nem tão pouco como 
privilégio epistêmico, mas como potencialidade emancipatória (WYLIE, 2003)

para colaborar, com a claridade pragmática possível à densidade da experiência, numa "epistemologia das consequências" (SANTOS, 2007, p. 33).

\section{Conclusão}

O alcance galopante das ciências biomédicas a esferas de transformação dos corpos descentra o seu questionamento da regulação para processos de construção que suspendem a divisa entre humano e não humano, mas também entre política e ontologia (MOLL, 2008). Em face disso, alguns autores vêm repensando a interseção entre a ciência moderna e a vida social à luz de uma intervenção tecnológica que não se restringe mais a uma ação normalizadora da biologia humana, mas que esculpe a sua substância, propondo pensarse esse processo como "biomedicalização" (CLARKE et al., 2003, p. 162). A emergência desse horizonte apela a quadros analíticos que abranjam os trânsitos entre as balizas oposicionais que têm guiado, historicamente, a epistemologia moderna. O deslocamento dessas balizas inspira, para Quintais (2007) a "mais desconcertante fluidez tectônica de que há memória” (QUINTAIS, 2007, p. 83), indicando, com isso, a crescente dificuldade em pensar, separadamente, a natureza da cultura. Não é ao acaso que o autor emprega o termo desconcertante. $\mathrm{Na}$ verdade, a crescente transação entre humanos e não humanos envolve não apenas uma crise epistemológica, mas aventa, também, a necessidade de entalhar o ético e o político no fazer da ciência. A isto chamou a atenção Boaventura de Sousa Santos em Um discurso sobre as ciências.

Propus discutir, aqui, a hipótese de uma transição paradigmática (SANTOS, 1987) a partir do campo disciplinar da biomedicina, argumentando que uma das virtualidades analíticas dessa hipótese é a plasticidade com que permite cobrir processos emergentes, marcados pela ambivalência. Perante a pressão social por uma expansão do campo da biomedicina a novos objetos e metodologias, as suas fronteiras históricas sofrem uma turbulência que demanda a inclusão de idiomas derivados das ciências sociais. Porém, um outro saber vem forçando, igualmente, a entrada nos seus universos epistêmicos: um saber fenomenológico, historicamente marginalizado como subjetividade. Identificando-o com um senso comum pragmático e emancipatório, propus que a contração do músculo regulatório da ciência moderna, impõe a exposição da sua imbricação num "senso 
comum conservador" (SANTOS, 2000, p. 101). Procurei, assim, demonstrar o caráter preponderantemente discursivo da "primeira ruptura epistemológica" (SANTOS, 1989, p. 33 e 2000, p. 100), defendendo que o exercício de uma "dupla ruptura epistemológica" (SANTOS, 1989, p. 39 e 2000, p. 101) opera na transformação do nexo entre a ciência moderna e o senso comum que, embora invisibilizado, não cessou de existir. Finalmente, a especificidade da substanciação das ciências biomédicas como relação social, suscita a necessidade de desvelar as relações de poder inter-escalares que recortam a heterogeneidade das suas práticas, por um lado, e induz à conclusão que um uso emancipatório das suas tecnologias depende da inclusão do saber experiencial na "trajetória" (SANTOS, 2000, p. 74) pela qual o conhecimento é produzido, por outro. Por conseguinte, a proposta de uma "ecologia de saberes" (SANTOS, 2006, p. 143 e 2007, p. 26) oferece valências particularmente adequadas ao campo da saúde, nomeadamente por alcançar a inclusão desse Outro do saber biomédico: o paciente. Nesse desenho, a validação do conhecimento não advirá de uma testemunha distanciada (SHAPIN; SCHAFFER, 1985) mas de uma testemunha que fala a partir do corpo-próprio. Considerando o estatuto subalterno da última no universo biomédico (HAHN; KLEINMAN, 1983) desenvolver a proposta de Boaventura de Sousa Santos no campo da saúde, implica questionar, na esteira de Spivak (1993), se pode a testemunha modesta falar?

\section{Referências}

BARNES, C.; OLIVER, M.; BARTON, L. (Org.). Disability studies today. Cambridge: Polity Press, 2002.

BARNES, C.; MERCER, G. Disability. Cambridge: Polity Press, 2003.

BASTOS, C. Ciência, poder, acção: as respostas à Sida. Lisboa: Imprensa de Ciências Sociais, 2002. BENCHIMOL, J.L.; ROMERO SÁ, M. Adolpho Lutz e as controvérsias sobre a transmissão da lepra por mosquitos. História, Ciências, Saúde - Manguinhos, v. 10, n. 1, p. 49-93, 2003. BIEHL, J. Will to live: Aids therapies and the politics of survival. Princeton: University Press, 2007. CAMARGO JR., K.R. A biomedicina. Physis, Rio de Janeiro, v. 15 (supl.), p. 177-201, 2005. CANGUILHEM, G.. The normal and the pathological. New York: Zone Books, 1991. CARDOSO, M.A. Sofrer sem dor: estudo etnográfico sobre o fim da vida num contexto de doença em fase terminal. 2005. Dissertação (Mestrado em Ciências Sociais) - Instituto de Ciências Sociais, Universidade de Lisboa, 2005. 
CARDOSO, M.A. Manual de tratamento da dor crónica. Lisboa: Lidel, 1999.

CONRAD, P. Medicalization and social control. Annual Review of Sociology, v. 18, p. 20932, 1992.

CLARKE, A.E. et al. Biomedicalization: technoscientific transformations of Health, illness, and U. S. biomedicine. American Sociological Review, v. 68, p. 161-194, 2003.

CSORDAS, T.J. Embodiment as a paradigm for anthropology. Ethos, v. 18, p. 5-47, 1990.

CRUZ, A. Terrenos incertos: antropologia e consciência. Antropologia Portuguesa, v. 20-21, p. 109-13, 2003/2004.

CRUZ, A. A lepra, entre a opacidade do véu e a transparência do toque: interstícios de sentido na última leprosaria portuguesa. 2008. Dissertação (Mestrado em Pós-Colonialismos e Cidadania Global) - Faculdade de Economia/Centro de Estudos Sociais da Universidade de Coimbra, 2008.

DESCARTES, R. Discours de la méthode. Paris: Librarie Philosophique J. Vrin, 1938.

DIRECÇÃO GERAL DE SAÚDE. Programa Nacional de Controlo da Dor. 2008.

Disponível em: <http://www.dgsaude.pt/upload/membro.id/ficheiros/i005651.pdf>. Acesso em: 15 mar. 2009.

DOUGLAS, M. Pureza e perigo: ensaio sobre as noçôes de poluição e tabu. Lisboa: Edições 70, 1991.

DUSSEL, E. Politica de la liberación: historia mundial y crítica. Madrid: Editorial Trotta, 2007.

EDMOND, R. Leprosy and Empire: a medical and cultural history. Cambridge: Cambridge University Press, 2006.

FALCÃO, Z. A lepra em Portugal. Lisboa: Academia Real das Ciências de Lisboa, 1900.

FARMER, P. Pathologies of power: health, human rights, and the new war on the poor. Berkeley: University of California Press, 2005.

FARMER, P. Partner to the poor: a Paul Farmer Reader. Berkeley and Los Angeles: University of California Press, 2010.

FLECK, L. Genesis and development of a scientific fact. Chicago: The University of Chicago Press, 1979.

FOUCAULT, M. Discipline and punish: the birth of the prison. London: Penguin Books, 1977a. . Michel. O nascimento da clínica. Rio de Janeiro: Forense-Universitária, 1977b.

GALISON, P.; STUMP, D.J. (Orgs.). The disunity of science: boundaries, contexts and power. California: Standford University Press, 1996.

GARLAND-THOMSON, R. Integrating disability, transforming feminist theory. In: DAVIS, L.J. (ed). The disability studies reader. New York: Routledge, 2006, p. 257-273.

GILROY, P. Between camps: race, identity and nationalism at the end of the colour line. London: The Penguin Press, 2000. 
GIORDANO, J.; SCHATMAN, M.E. A crisis in chronic pain: an ethical analysis. Pain Physician, v. 11, p. 589-595, 2008.

GOOD, B.J. Medicine, rationality and experience: an anthropological perspective. Cambridge: Cambridge University Press, 1994.

GOULD, T. A disease apart: leprosy in the modern world. New York: St. Martin's Press, 2005. GRAMSCI, A. Letters from prison. New York: Columbia University Press, 1994.

HAHN, R.A.; KLEINMAN, A. Biomedical practice and anthropological theory: frameworks and directions. Annual review of anthropology, v. 12, p. 305-333, 1983.

HAHN, R.A. Sickness and healing: an anthropological perspective. Michigan: Yale University, 1995.

HARAWAY, D.J. Situated Knowledge: The Science Question in feminism and the Privilege of Partial Perspective. Feminist Studies, v. 14, n. 3. p. 575-599, 1988.

.. Modest witness: feminist diffractions in science studies. In: GALISON, P.; STUMP, D.J. (Orgs.). The disunity of science: boundaries, contexts and power. California: Stanford University Press, 1996, p. 428-441.

HARDING, S. Is science multicultural? Postcolonialisms, feminisms and epistemologies. Bloomington: Indiana University Press, 1998.

. Rethinking standpoint: theory epistemology: what is "strong objectivity"? In: (Org.), The feminist standpoint reader: intellectual and political controversies. New York: Routledge, 2002, p. 127-140.

JACKSON, J. Chronic pain and the tension between the body as subject and object. In: CSORDAS, Thomas (Org.), Embodiment and experience: the existential ground of culture and self. Cambridge: Cambridge University Press, 1994, p. 201-228.

KLEINMAN, A. et al. Pain as human experience: an introduction. In: GOOD, M.D. et al. (Orgs.). Pain as human experience: an anthropological perspective. Berkeley: University of California Press, 1994, p. 1-28.

KUHN, T.S. A estrutura das revoluçôes cientificas. São Paulo: Perspectiva, 2005.

LATOUR, B. Les microbes: guerre et paix suivi de irreductions. Paris: Editions A. M. Métailié, 1984. . Jamais fomos modernos. Rio de Janeiro: Editora 34, 1994.

LEDER, D. The absent body. Chicago: The University of Chicago Press, 1990.

LIMA, M.A.G. de; TRAD, L.A.B. Dor crônica: objecto insubordinado. História, Ciências, Saúde-Manguinhos, Rio de Janeiro, v. 15, n. 1, p. 117-133, 2008. 
LOCK, M. Alienation of body parts and the biopolitics of immortalized cells. In: LOCK, M.; FARQUHAR, J. (Orgs.). Beyond the body proper: reading the anthropology of material life. London: Duke University Press, 2007, p. 567-583.

LOCK, M.; KAUFERT, P.A. Introduction. In: LOCK, M.; KAUFERT, P.A. (Orgs.). Pragmatic women and body politics. Cambridge, Cambridge University Press, 1998, p. 1-27.

LOCK, M.; NGUYEN, V-K. An anthropology of biomedicine. Oxford: Wiley-Blackwell, 2010. MARMOT, M. Introduction. In: MARMOT, M.; WILKINSON, R.G. (Orgs.). Social determinants of health. Oxford: Oxford University Press, 2006, p. $1-5$.

MARTIN, E. The egg and the sperm: how science has constructed a romance based on stereotypical male-female roles. In: LOCK, M.; FARQUHAR, J. (Orgs.). Beyond the body proper: reading the anthropology of material life. London: Duke University Press, 2007, p. $417-427$.

MERLEAU-PONTY, M. Fenomenologia da percepção. São Paulo: Martins Fontes, 1999.

MOLL, A. Política ontológica: algumas ideias e várias perguntas. In: NUNES, J.A.; ROQUE, R. (Orgs.). Objectos impuros: experiências em estudos sobre a ciência. Porto: Afrontamento, 2008, p. 63- 106.

NAGEL, T. What it is like to be a bat? Philosophical Review, v. 83, n. 4 p. 435-50, 1974. Disponível em: < http://members.aol.com/NeoNoetics/Nagel_Bat.html> Acesso em 11-10-2005.

NUNES, J.A. O resgate da epistemologia. Revista Critica de Ciências Sociais, v. 80, p. 45-70, 2008.

OREM, D.E. Reflections on nursing practice science: the nature, the structure and the foundation of nursing sciences. Self-care and dependent-care nursing, v. 13, p. 4-11, 2004.

PAIVA, E. Os significados plurais da especialização em dor crónica para a humanização dos cuidados. Economia e Sociologia - Évora, v. 83, p. 55-66, 2007.

PÁLSSON, G.; HARDARDÓTTIR, K.E. For whom the cell tolls: debates about biomedicine. Current Anthropology, v. 43, n. 2, p. 271-287, 2002.

PANDYA, S.S. The First International Leprosy Conference, Berlin, 1897: the politics of segregation. História, Ciências, Saúde-Manguinhos, v. 10, n. 1, p. 161-77, 2003.

PETRYNA, A. Life exposed: biological citizens after Chernobyl. Princeton: Princeton University Press, 2002.

QUIJANO, A. Coloniality of power, eurocentrism, and social classification. In: MORAÑA, M.; DUSSEL, E.D.; JÁUREGUI, C.A. (Orgs.). Coloniality at Large: Latin America and the Postcolonial Debate. London: Duke University Press, 2008, p. 181-224. 
QUINTAIS, L. Fluidez tectónica. As bio-tecno-ciências, a bio-arte e a paisagem cognitiva do presente. Revista Crítica de Ciências Sociais, v. 79, p. 79-94, 2007.

ROSE, N. The politics of life itself: biomedicine, power and subjectivity in the twenty-first century. Princeton: Princeton University Press, 2007.

SANTOS, B. de S. Um Discurso sobre as Ciências. Porto: Afrontamento, 1987.

. Introdução a uma ciência pós-moderna. Porto: Afrontamento, 1989.

- A crítica da razão indolente: contra o desperdício da experiência. Porto: Edições

Afrontamento, 2000.

- Os processos de globalização. In:

(Org.). Globalização: fatalidade ou

utopia? Porto, Afrontamento, 2001, p. 33-106.

. A gramática do tempo: para uma nova cultura política. Porto: Afrontamento, 2006.

- Para além do pensamento abissal: das linhas globais a uma ecologia dos saberes.

Revista Crítica de Ciências Sociais, v. 78, p. 3-46, 2007.

SCARRY, E. The body in pain: the making and unmaking of the world. Oxford: Oxford University Press, 1985.

SHAPIN, S.; SCHAFFEER, S. Leviathan and the Air-Pump: Hobbes, Boyle, and the experimental life. Princeton: Princeton University Press, 1985.

SINGER, M.; BAER, H. Critical medical anthropology. New York: Baywood Publishing Company, 1995.

SOARES, J.C.R.S.; CAMARGO Jr., K.R. A autonomia do paciente no processo terapêutico como valor para a saúde. Interface: Comunicação, Saúde, Educação, v. 11, n. 21, p. 65-78, 2007. SONTAG, S. Illness as metaphor and Aids and its metaphors. London: Penguin Books, 1991. SPIVAK, G.C. Can the subaltern speak? In: WILLIAMS, P.; CHRISMAN, L. (Orgs.). Colonial discourse and post-colonial theory. Harlow: Longman, 1993, p. 66-111.

VALLA, V.V. Globalização, a questão social e a nova pobreza. In: VALLA, V.V.; STOTZ, E.N.; ALGEBAILE, E. B. (Orgs.). Para compreender a pobreza no Brasil. Rio de Janeiro: Contraponto, 2005, p. 33-52.

VIGARELLO, G. O limpo e o sujo: a higiene do corpo desde a Idade Média. Lisboa: Fragmentos, 1985.

VERHAAK, P.F.M. et al. Prevalence of chronic benign pain disorder among adults: a review of the literature. Pain, v. 77, p. 231-239, 1998.

WALLERSTEIN, I. World-systems analysis: an introduction. Durham and London: Duke University Press, 2007.

WYLIE, A. Why standpoint matters. In: FIGUEROA, R.; HARDING, S. (Orgs.). Science and other cultures: issues in philosophies of science and technology. New York: Routledge, 2003, p. 49- 69. 
${ }^{1}$ Para uma sinopse do conceito de medicalização, ver Lock e Nguyen (2010, p. 67-71).

${ }^{2}$ Note-se que esta ontologia não é estranha à cosmovisão judaico-cristã, cujo assento é, precisamente, uma série de divisões binárias que radicam na distinção entre corpo e alma (DUSSEL, 2007). Curiosamente, Leder (1990) defende que o dualismo cartesiano tem inspiração nos universos fenomenológicos da experiência corporal.

${ }^{3}$ Good (ver 1994, p. 84) argumenta que ao racional, técnico e fisiológico se justapõem o existencial e o soteriológico na prática clínica. Já Taussig (TAUSSIG apud SINGER; BAER, 1995, p. 27), referindo-se à mesma inclinação humanista e heroica do discurso biomédico, denuncia "a aura de benevolência da biomedicina”, que sancionaria intervençôes de feição colonialista sobre o corpo e grupos populacionais subalternos.

${ }^{4}$ Universalização essa que se efetua menos por via da epistemologia e mais pela da estabilização de redes de prática da ciência (LATOUR, 1994; SHAPIN; SCHAFFEER, 1985).

${ }^{5}$ A crítica feminista denuncia a biomedicina como uma "instituição patriarcal" (LOCK; NGUYEN, 2010, p. 70), pela sua abordagem do corpo feminino e da reprodução como espaços que demandam uma intervenção tecnológica e normalizadora.

${ }^{6}$ Também os estudos sociais de deficiência arremessam uma crítica à jurisdição biomédica na definição do que é deficiência, denunciando a ontologização que promove daquela, ao elaborar uma acepção centrada no indivíduo, contrapondo que a deficiência é uma categoria social e culturalmente construída, com inerentes pressupostos políticos que se consumam nas barreiras que a sociedade erige à inclusão das pessoas portadoras de deficiência. Em vez de identificar a deficiência como uma limitação individual, o modelo social identifica a sociedade como sendo ela mesma restritiva, expondo a relação entre a escultura histórica da deficiência na modernidade ocidental e o capitalismo industrial que emergiu no bojo da última como sistema econômico assente numa determinada ordem produtiva e laboral (BARNES; MERCER, 2003; BARNES; OLIVER; BARTON, 2002).

7 Para uma discussão aprofundada acerca da autonomia do paciente no processo terapêutico, ver Soares e Camargo Jr. (2007).

${ }^{8}$ Não cabe aqui uma discussão sobre dois desdobramentos centrais à reivindicação de uma participação leiga como "senso comum emancipatório" (SANTOS, 2000, p. 101) na forja e avaliação da ciência. Porém, vale a pena rememorar, por um lado, o dissenso entre Harding (2008) e Haraway (1988), em que a primeira propõe que as forças sociais constritivas são mais bem apreendidas nas margens como "espaços de possibilidades epistemológicas radicais" (HARDING, 2008, p. 118) e a segunda argumenta que qualquer conhecimento é situado e, por conseguinte, parcial, estendendo a necessidade de uma problematização crítica ao conhecimento produzido nas margens e defendendo que a superação do relativismo que exaura a política da epistemologia, só pode ser obrada através de um questionamento crítico do aparato com que se mira e de uma interconexão horizontal entre diferentes, e necessariamente parciais, olhares historicamente enraizados. Por outro lado, ambas as propostas colidem na antinomia Durkheimiana (ver CRUZ, 2003/2004) entre social e indivíduo, atribuindo a objectividade forte (HARDING, 2002) somente a conhecimentos situados de feição colectiva, falhando em reconhecer que o ponto de vista incorporado é pré-objectivo (CSORDAS, 1990) o que denota que os significados tecidos na experiência não se constringem a saberes colectivamente construídos, como patenteia o provocatório ensaio de Nagel (1974) sobre como será para um morcego ser um morcego, tanto mais para o caso de uma "epistemologia das consequências" (SANTOS, 2007, p. 33) da acção biopolítica sobre o corpo. 


\section{Abstract}

\section{Can the modest witness speak? Biomedicine within a paradigmatic shift}

This essay aims to discuss the hypothesis posed by Boaventura de Sousa Santos in Um discurso sobre as ciências, that modern science is going through a paradigmatic shift. By grounding this reflection on the disciplinary field of biomedicine, this essay will try to deepen the proposal for a "double epistemological rupture" that might promote a "prudent knowledge for a decent life". From the examination of the ideological filaments that weave the epistemological matrix of biomedicine, as well as of its heterogeneous substantiation as a social practice mediated by power relations, it will be argued that the "first epistemological rupture" between modern science and common sense was mostly discursive, and that for which reason it is precisely on the transformation of that bound (which although invisibilized didn not cease to exist) that a "double epistemological rupture might be operated. For that purpose, it will be proposed, from the analysis of the contemporaneous expansion of the field of biomedicine to encompass objects and methodologies which destabilize modern dichotomies, that the phenomenological and historically marginalized knowledge of the patient should be considered as an emancipatory common sense which enables the production of an "epistemology of consequences". As such, the modest witness to modern science could be transformed into a subaltern witness who speaks from the experiential density of the Self's body which encompasses its social positioning.

> Key words: epistemology; biomedicine; common sense; experience; emancipation; witness 